\title{
A RETROSPECTIVE STUDY OF ATTEMPTED SUICIDE CASES ADMITTED INTO CRITICAL CARE UNIT OF A TERTIARY CARE HOSPITAL
}

\author{
Pawan $^{1}$, Sowmya Rohith ${ }^{2}$, Rangalakshmi S3, Chaitanya Kamat 4 \\ ${ }_{1}^{1}$ Assistant Professor, Department of Anaesthesia, Rajarajeswari Medical College \& Hospital, Bangalore. \\ ${ }^{2}$ Assistant Professor, Department of Anaesthesia, Bangalore Medical College, Bangalore. \\ ${ }^{3}$ Professor, Department of Anaesthesia, Rajarajeswari Medical College \& Hospital, Bangalore. \\ ${ }^{4}$ Assistant Professor, Department of Anaesthesia, JNMC Medical College \& Hospital, Belgaum.
}

\begin{abstract}
A suicide is a deliberate act of self-harm taken with the expectation that it will be fatal. Suicide remains a significant public health problem worldwide. It not only burdens the people related personally, but financially, emotionally leaving a permanent scar psychologically. Suicide is a personal tragedy that prematurely takes the life of an individual leaving a social and psychological stigma on the family, friends and communities. About 9,00,000 people die of suicide worldwide every year according to WHO. Of these, 1,70,000 are residents of India. ${ }^{1}$ Between 1987-2007, the suicide rate has increased from 7.9 to 10.3 per $1,00,000$ with higher suicide rates in southern and eastern states of India. ${ }^{2}$ According to Government of India, suicide deaths are as high as $1,35,000$ in the year $2010 .^{3}$ The WHO has estimated that approximately one suicide occurs every minute and one suicide attempt approximately every 3 seconds (WHO-figures and facts about suicide 1999). The majority of suicides in India are by those below the age of 30 years. The fact that $71 \%$ of suicides in India are by persons below the age of 44 years imposes a huge social, economical and emotional burden on our society. The near equal suicide rates of young men and women and consistently narrow male to female ratio of 1.4:1 denotes that Indian women die more. ${ }^{2}$ Suicide cases contribute to a major proportion of case load on intensive care units; about $55-60 \%$ of burden in ICU.
\end{abstract}

KEYWORDS: Suicide, Critical Care.

HOW TO CITE THIS ARTICLE: Pawan, Sowmya Rohith, Rangalakshmi S, Chaitanya Kamat. "A Retrospective Study of Attempted Suicide Cases Admitted into Critical Care Unit of a Tertiary Care Hospital." Journal of Evolution of Medical and Dental Sciences 2015; Vol. 4, Issue 93, November 19; Page: 15885-15887, DOI: 10.14260/jemds/2015/2307.

INTRODUCTION: OBJECTIVE: The study is a retrospective study conducted in the ICU of Rajarajeswari Medical College and Hospital, Bangalore, tertiary care centre over a period of 5 years spanning between January 2010 - July 2014. The objective of our study was to compile the data obtained from all the cases of suicide for demographic factors like age, marital status, mode of suicide, etc.

METHODOLOGY: After the ethical committee clearance, the data has been collected from the hospital records. All the 452 cases of suicide which were admitted to the ICU were analyzed retrospectively. Demographic variables like age, sex, marital status, mode of suicide, history of previous psychiatric history and cause of death were tabulated and analyzed. The descriptive statistics obtained were analyzed by statistical software 9.2 .

RESULTS: The study recruited 452 patients of which $53 \%$ were male. The following table shows gender wise distribution of patients.

Financial or Other, Competing Interest: None.

Submission 02-11-2015, Peer Review 03-11-2015,

Acceptance 09-11-2015, Published 19-11-2015.

Corresponding Author:

Dr. Sowmya Rohith,

Department of Anesthesia,

Bangalore Medical College,

Bangalore.

E-mail: dr.soumyarohit@gmail.com

DOI:10.14260/jemds/2015/2307.

\begin{tabular}{|c|c|c|}
\hline Gender & Numbers & Percentage \\
\hline Male & 239 & $53 \%$ \\
\hline Female & 213 & $47 \%$ \\
\hline \multicolumn{3}{|c|}{ Table1: Gender Distribution } \\
\hline
\end{tabular}

In our study it is noted that there is a slight increase in suicide rates in male population with a female to male ratio of $1: 1.1$, which is statistically insignificant.

\begin{tabular}{|c|c|c|}
\hline AGE & $\begin{array}{c}\text { No. of Cases of } \\
\text { Suicide }\end{array}$ & Percentage \\
\hline$<20 \mathrm{yrs}$ & 79 & $17 \%$ \\
\hline $21-50 \mathrm{yrs}$ & 347 & $77 \%$ \\
\hline$>50 \mathrm{yrs}$ & 26 & $6 \%$ \\
\hline \multicolumn{3}{|c|}{ Table 2: Age Distribution } \\
\hline
\end{tabular}

Majority of the suicide cases fall in the age group of 21 50 yrs and its noted that the suicide rate drastically fell after 50 yrs to $6 \%$.

\begin{tabular}{|c|c|c|}
\hline Marital Status & $\begin{array}{c}\text { No. of Cases of } \\
\text { Suicide }\end{array}$ & Percentage \\
\hline Married & 285 & $63 \%$ \\
\hline Single & 167 & $37 \%$ \\
\hline \multicolumn{3}{|c|}{ Table 3: Marital Status } \\
\hline
\end{tabular}

It's seen in the study that married group had a higher rate of suicide at $63 \%$ compared to singles group. 


\begin{tabular}{|c|c|c|c|c|}
\hline $\begin{array}{c}\text { Modes of } \\
\text { Suicide }\end{array}$ & $\begin{array}{c}\text { No. of } \\
\text { Patients }\end{array}$ & $\begin{array}{c}\text { Percentage } \\
\text { of Total } \\
\text { (Mean-452) }\end{array}$ & $\begin{array}{c}\text { Mortality } \\
\text { (\%) }\end{array}$ & $\begin{array}{c}\text { Mean } \\
\text { Age in } \\
\text { Years }\end{array}$ \\
\hline $\begin{array}{c}\text { Aluminium } \\
\text { phosphate } \\
\text { poison }\end{array}$ & 5 & $1.1 \%$ & $3(60 \%)$ & 26.4 \\
\hline Corrosive & 4 & $0.88 \%$ & $2(50 \%)$ & 34.5 \\
\hline DDT & 2 & $0.44 \%$ & $1(50 \%)$ & 24.5 \\
\hline Formalin & 1 & $0.22 \%$ & - & 19 \\
\hline Hanging & 31 & $6.85 \%$ & $9(29 \%)$ & 29.3 \\
\hline Rat poison & 35 & $7.74 \%$ & $8(22.85 \%)$ & 27.5 \\
\hline $\begin{array}{c}\text { Tablet } \\
\text { consumption }\end{array}$ & 82 & $18.14 \%$ & $1(1.2 \%)$ & 28.5 \\
\hline $\begin{array}{c}\text { Kerosene } \\
\text { poison }\end{array}$ & 2 & $0.44 \%$ & - & 17.5 \\
\hline $\begin{array}{c}\text { Nail polish } \\
\text { remover }\end{array}$ & 1 & $0.22 \%$ & - & 21 \\
\hline OP poison & 258 & $57.07 \%$ & $18(6.97 \%)$ & 31 \\
\hline $\begin{array}{c}\text { OP compound+ } \\
\text { rat poison }\end{array}$ & 1 & $0.22 \%$ & - & 16 \\
\hline Phenol poison & 6 & $1.32 \%$ & $1(16.6 \%)$ & 24.8 \\
\hline $\begin{array}{c}\text { Spirit } \\
\text { consumption }\end{array}$ & 2 & $0.44 \%$ & - & 24.5 \\
\hline Unknown & 22 & $4.86 \%$ & - & 26.7 \\
\hline \multicolumn{2}{|c|}{ Table 4: Modes of Suicide } & \\
\hline
\end{tabular}

The data shows that most common mode of suicide is poisoning out of which, OP poisoning is the most preferred method with a mortality of $6.97 \%$, followed by hanging with a mortality of $29 \%$.

\begin{tabular}{|c|c|c|}
\hline Total Cases of Suicide & $\mathbf{4 5 2}$ & \\
\hline Patients with psychiatric history & 63 & $14 \%$ \\
\hline $\begin{array}{l}\text { Previous suicide attempts among } \\
\text { patients with psychiatric history }\end{array}$ & 3 & $4 \%$ \\
\hline
\end{tabular}

Table 5: History of Previous Psychiatric Illness

Among the 452 suicide patients $14 \%$ of them had history of psychiatric illness and out of these 63 patients $4 \%$ of the patients had history of previous suicide attempt.

\begin{tabular}{|c|c|}
\hline No. of Patients Attempted Suicide & $\mathbf{4 5 2}$ \\
\hline No. of patients revived & $408(91.3 \%)$ \\
\hline No. of patients succumbed to death & $44(9.7 \%)$ \\
\hline \multicolumn{2}{|c|}{ Table 6: Treatment Outcome } \\
\hline
\end{tabular}

Mortality rate in the present study is $9.7 \%$.

DISCUSSION: In our study 452 patients have been recruited, out of which $53 \%$ belonged to male population with male to female ratio of 1.1:1. A slight male predominance is noted, though this is not statistically significant. In the studies done by Bansal et al. ${ }^{4}$ And Nagendra et al. ${ }^{5}$ Male patients committing suicide outnumbered females.

In another study by Ramdurg et al. ${ }^{6}$ The gap between male and female suicide rates was negligible. In the western countries the statistics show that majority of the suicide attempters were females. ${ }^{6}$ In a study by Sahin et al. ${ }^{7}$ Noted a predominance of suicides in females $(75.4 \%)$ compared to males. WHO report says that more males committed suicide compared to females in majority of countries.

Most of the patients in our study belonged to the age group of $21-50 \mathrm{yrs}$, which accounts for $77 \%$ of the study population. Patients belonging to the age group of less than $20 \mathrm{yrs}$ were $17 \%$ and only $6 \%$ were in the age group of above $50 \mathrm{yrs}$.
According to the Million Death Study (MDS), registrar general of India $2010^{1} 40 \%$ of the suicide deaths were noted in the age between 15 and 29yrs.

In the present study, $63 \%$ of the patients married compared to $37 \%$ of the singles. In the MDS study $66 \%$ of the males, $63 \%$ of the females were married and $6 \%$ of women belonged to divorcee group. In a study by Subhadip Bharati et al. 8 42.9\% were married.

In our study it is noted that $14 \%$ were on some kind of psychiatric therapy before the suicide attempt, out of which $4 \%$ had attempted suicide in the past. In a study by Subhadip Bharati et al. $817 \%$ of the patients were mentally ill and out of these $17.3 \%$ had a history of previous suicidal attempt and it was also noted that $20.5 \%$ had a family history of suicide. ${ }^{8}$ Studies by Chandrashekar et al., Also showed similar results. ${ }^{9}$

The predominant mode of attempted suicide in our study has been organophosphorus compound poisoning with incidence of $57 \%$ followed by rat poisoning at $8 \%$ and hanging at $7 \%$ as third important mode. Most common mode of suicide in Asian population is use of organophosphorus pesticide used in agriculture as per studies of Gunnell D. ${ }^{10} \mathrm{~A}$ systematic review of world data from 1990-2007 estimated that around $30 \%$ of global suicides are due to pesticides self poisoning. ${ }^{9}$ In our study, $9.7 \%$ was the mortality rate. According to Million Death Study (MDS), the mortality rate is $14 \%$.

CONCLUSIONS: Suicide is the result of a complex interaction between individual vulnerabilities and family problems, financial difficulties, stress of modern life and preexisting mental illness to name a few. Most of the times taboo, stigma, shame and guilt obscure the suicidal behavior barring the patient from seeking proper support and therapy. Lack of awareness on the part of the patient about help groups also contributes to this.

Destigmatization of mental illness contributes in a big way in countering the scourge of suicide. Problem support groups, health systems and societies should play a proactive role in preventing suicides. A comprehensive, integrated and synergistic approach will contribute in decreasing the rate of suicide.

The role of clinicians and psychologists working in health care systems is crucial in identifying those at risk for suicide and in imparting timely support, thus playing a pivotal role in prevention of suicide. Role of ICU is crucial in resuscitation with a good supportive care and appropriate and timely treatment in salvaging many precious lives, thus decreasing the mortality rate. Appropriate legislations are to be made by the government for the purchase and storage of the pesticides for agriculture use. These stringent rules with proper ratifications in the existing laws may help in bringing down the rate of suicides in agricultural societies.

A collective and coordinated effort from families, social organizations, health care systems and government will help in controlling the evil called suicide. 


\section{BIBLIOGRAPHY:}

1. Vikram Patel, Chinthanie Ramasundarahettige, Lakshmi Vijayakumar, J S Thakur, Vedhan Gajalakshmi, Wilson Suraweera, Prabhat Jha, for Million Death Study Collaborators. Suicide mortality in India: A nationally representative survey. The Lancet. 2012; June;379:23432351.

2. Vijaykumar L. Suicide and its prevention: The urgent need in India. Indian J Psychiatry 2007; 49:81-4.

3. National Crime Records Bureau, Accidental deathsand suicides in India. New Delhi: Ministry Of Home Affairs, Govt Of India 2008.

4. Bansal P, Gupta A, Kumar R. The Psychopathology and the Socio-demographic Determinants of Attempted Suicide Patients. Journal of Clinical and Diagnostic Research 2011;5(5):917-920.

5. NagendraGouda MR, Rao S M. Factors related to attempted suicide in Davanagere. Indian J of Community Medicine. 2008;33(1):15-18.
6. Ramdurg S, Goyal S, Goyal P, Sagar R, Sharan P. Sociodemographic profile, clinical factors, and mode of attempt in suicide attempters. Industrial Psychiatry Journal.2011; 20(1):11-16.

7. Sahin HA, Sahin I, Arabaci F. Sociodemographic factors in organophosphate poisoning; a prospective study. Hum Exp Toxicol.2003 Jul;22(7):349-53.

8. Subhadip Bharati, Sharmila Mallik, Pratyay Pratim Datta, Asish Mukhopadhyay, Debalina Datta, Sahina Haq. Sociodemographic profile and suicidal intent of attempted suicide cases: A hospital based Study in West Bengal, India. National Journal of Medical Research. 2013;3:122125.

9. R Chandrashekaran, J Gnaseelan, Ajith Sahai, R.P Swaminathan, Bojir Perme. Psychiatry and personality disorders in survivors following their first suicide attempt. Indian Journal of Psychiatry2003; 45(2):45-48.

10. Gunnel D, Eddleston M. Suicide bu intentional ingestion of pesticides: a continuing tragedy in developing countries. Int J Epidemiol 2003; 32: 902-09. 